\title{
ALGUNOS PRECURSORES ANDALUCES DE LA SOCIOLOGIA RURAL. PRIMERA PARTE: JUAN DIAZ DEL MORAL
}

Eduardo SEVILLA GUZMAN *

\section{NOTA INTRODUCTORIA}

En las páginas que siguen presento un análisis de los aspectos más relevantes para la sociología rural de la obra de varios intelectuales andaluces ${ }^{1}$. Tales aspectos se refieren exclusivamente al contenido de sus trabajos, ya que la inserción de éstos en los marcos sociales en los que aparecen ha sido realizada en otro lugar ${ }^{2}$.

Estudiaré, en esta primera parte a la figura central de nuestro análisis: Juan Díaz del Moral. No obstante también, en una segunda parte, consideraré la obra de Pascual Carrión y Blas Infante que, aún encontrándose a gran distancia de la de aquél, poseen elementos de indudable valor para la sociología rural. Todos ellos pueden, en rigor, ser considerados como precursores de la sociología rural.

\section{EL CAMPESINADO COMO FUERZA SOCIAL}

Para comprender en forma adecuada el significado de la obra de Díaz del Moral hay que conocer, no obstante, determinados aspectos de su vida profesional. Díaz del Moral se instala en Bujalance, pueblo eminentemente

* Instituto de Sociología y Estudios Campesinos. Universidad de Córdoba.

1. Tal calificación tiene, en estos papeles, un sentido lato, como acto de voluntad (es andaluz quien quiere serlo) más que como un hecho demográfico. Dicha calificación no posee, empero, un carácter subjetivo o arbitrario; se desprende, por el contrario, de la identificación de la obra de un autor con la problemática de Andalucia y el deseo de buscar soluciones para la misma.

2. Cfr. E. Sevilla Guzmán, "Perspectivas sociológicas en el pensamiento social agrario español", en el I Congreso de Sociología de la Féderación de Asociaciones de Sociología del Es tado Espaìol, Zaragoza, 24-27 de Septiembre de 1981. Trabajo éste del que proceden los materiales con que hemos elaborado este estudio. Una versión bastante reducida del mismo puede verse en $H$. Newby y E. Sevilla Guzmán, Introducción a la sociología rural. (Madrid: Alianza Universidad, 1984), pp. 167-205. 
jornalero de la campiña de Córdoba, como Notario (a petición propia y renunciando a otros destinos urbanos) al finalizar el siglo $\mathrm{XIX}^{3}$. Esto sucede en el momento en que el campesinado, bajo la influencia de las ideas de la Primera Internacional y la organización de las primeras sociedades obreras en nuestro país, inicia en Andalucía un movimiento, anarquista en su inspiración, de luchas sociales. Juan Díaz del Moral presencia directamente en Bujalance las primeras huelgas generales de 1903, así como los conflictos de 1905 y las grandes huelgas de 1918 a 1920. Desde el principio queda vivamente impresionado por la filosofía que se escondía en el trasfondo de aquellas acciones. Creyó ver en éstas una concepción del mundo típicamente campesina, un "socialismo indígena" 4 , que sostenía la idea de libertad social como forma de relación entre los seres humanos en un nuevo orden moral del mundo. Ello le lleva a estudiar a fondo en forma sistemática, por un lado, la génesis y desarrollo del movimiento campesino en España y en forma especial en Andalucía y, por otro, el movimiento obrero que surge a nivel mundial con la aparición del capitalismo, al objeto de insertar aquél en éste y tratar de entender el "socialismo indígena" que percibió en sus paisanos. Para Díaz del Moral "las luchas de los campesinos cordobeses, como las del resto de Andalucía, no son más que un episodio de la historia del problema social español y aún del mundial... Sería imposible entender las conmociones de esta región sin tener presente las demás de los países civilizados: el movimiento proletario es uno de los hechos más universales de la Historia" (DIAZ, op. cit., p. 22).

Esta concepción del campesinado como fuerza social es, sin duda, la aportación más sustancial de Díaz del Moral a la teoría sociológica. El trabajo en el que aparece tal aportación es su Historia de las agitaciones campesinas andaluzas que, aunque fuese publicado en 1929, quedó concluido en 1923. Aún cuando su hipótesis sobre la existencia de un "socialismo indígena", como conciencia de clase del campesinado cordobés, que se remonta al siglo XIV haya sido falseada ${ }^{5}$, su método de análisis y sus esfuerzos de contrastación empírica nos obligan a situarle entre los fundadores de la sociología rural como disciplina que adopta el método hipotético deductivo, como forma de contrastación con la realidad social.

La dimensión teórica que el notario de Bujalance introduce en su pesquisa al buscar precedentes de las acciones de clase del campesinado nos llevan a considerarle, no sólo como un precursor de la nueva tradición de estudios campesinos $^{6}$ sino como el pionero en utilizar el enfoque heterodoxo en la

3. Para un apasionado, pero sumamente rico en materiales y documentación, apunte biográfico Cf. Antonio Tastet Diaz, "Semblanza sobre la vida y obra de don Juan Diaz del Moral" Revista de Estudios Regionales n. ${ }^{\circ}$, Julio-Diciembre, 1979; pp. 283-356.

4. Juan Díaz del Moral, Historia de las agitaciones campesinas andaluzas 1, ${ }^{a}$ Ed. 1929 (Madrid: Alianza, 1973), p. 78.

5. Cf. A. Domínguez Ortíz, Alteraciones campesinas (Madrid: Narcea, 1973-), pp. 58 y ss. 85 y ss.

6. Sobre este tema cf. Angel Palerm, Antropología y marxismo (México: Nueva Imagen, 1980). E.P. 
definición del campesinado para el análisis de su acción política ${ }^{7}$. Sin embargo la parte más importante de su libro es aquella en la que estudia los movimientos campesinos cordobeses desde mediados del siglo XIX hasta 1923. En su análisis detecta en el campesinado cordobés un claro enfíntamiento al nuevo orden capitalista entonces emergente en España y con un rigor y objetividad, características éstas bastante inusuales en aquellos momentos, inserta estas acciones en el contexto del movimiento obrero internacional. Así, muestra como la acción campesina, espontánea en sus comienzos, surge de la mano de las nuevas políticas que republicanos y federalistas organizan en las coyunturas políticamente favorables ${ }^{8}$ y va adquiriendo, con la difusión de las ideas de la Primera Internacional y la organización de las primeras sociedades obreras en España y Andalucía, un carácter más organizado, por un lado, y una dimensión de acción social colectiva, por otro.

Su relato en este período comienza con análisis del levantamiento popular de Iznajar, que se conoce con el nombre de "la revolución de Loja" , donde más de seis mil campesinos armados lucharon contra el ejército durante cinco días. Tal levantamiento fue promovido por el republicano Rafael Pérez del Alamo ${ }^{10}$ que, después de recorrer parte del sur de la provincia de Córdoba reclutando militantes campesinos, se acantonó en su pueblo. Aún cuando tal movimiento tuviera una clara influencia masónica de tipo carbonario, sin duda poseía el respaldo de la conciencia histórica del campesinado, que había sido despojado de sus tierras (el socialismo indígena), ya que numerosos pueblos de Málaga, Granada, Jaén y Almería respondieron al llamamiento de Loja y procedieron a repartir las tierras colmando así sus aspiraciones. A partir de este momento Díaz del Moral relata la dinámica del movimiento campesino en términos que vienen a mostrar una progresiva toma de conciencia de clase. La revolución de septiembre de 1868, el motín de

Archetti y S; Aass "Peasant Studies: An Overview" en H. Newby (ed) International Perspectives in Rural Sociology (Chischester: John Wiley \& Sons, 1978; pp. 107-129 y H. Newby y E. Sevilla Guzmán Sociología rural. Análistis critico... op. cit. pp.

7. Sobre el enfoque heterodoxo en los estudios campesinos cf. E. Sevilla Guzmán y M. Pérez Yruela "Para una definición sociológica del campesinado" en Agricultura y Socicdad, n, $\mathbf{1}, 1976 ; \mathbf{p p}$. 15-39.

8. En la actualidad contamos con una valiosa aportación de Antonio Miguel Bernal sobre los primeros brotes de violencia campesina en Andalucía como consecuencia de la disolución del régimen señorial y las usurpaciones por parte de la nobleza a los pequeños propietarios y colonos mediante la calificación legal de "señorios territoriales" a las tierras de su jurísdicción y al posterior fallo a su favor de los "pleitos de señoríos" cf. A. Miguel Bernal La propiedad de la ticrra y las luchas agrarias andaluzas (Barcelona: Ariel, 1974) cf. especialmente pp. 114 y 22. Para un excelente anälisis global del proceso de apropiación de la tierra en Andalucía durante este período cf. A. M. Bernal La Lucha por la ticrra (Madrid: Taurus, 1979), passim.

9. Este suceso tuvo lugar en 1861 .

10. Díaz del Moral contó con un valioso documento para el análisis e interpretación de este suceso: el testimonio directo de su inspirador que, publicado en 1872 , fue reeditado como R. Pérez del Alamo Apuntes sobre dos revoluciones andaluzas (Madrid: ZYX, 1971). Este libro cuenta con un excelente estudio introductorio en Antonio Maria Calero insertando el documento histórico que constituye el relato del lider de aquella revuelta, en su contexto político y social. 
Montilla de 1873 son, entre otras acciones de protesta social y política, analizadas por Díaz del Moral; analizadas desde la perspectiva de su dimensión campesina, con una excelente documentación como apoyo empírico a sus escritos $^{11}$.

Paralelamente Díaz del Moral analiza los acontecimientos que desde la publicación del Manifiesto Comunista vendrían, a través de la constitución de la Asociación Internacional de trabajadores y la celebración de sus congresos, a robustecer y dar contenido ideológico al movimiento campesino ${ }^{12}$. Especial interés tiene el apasionado relato de Díaz del Moral hace de los acontecimientos que tienen lugar a nivel local. Valga de muestra la entusiasta descripción que hace del congreso internacionalista celebrado en Córdoba:

"La pacífica ciudad de los abderramanes vió turbado durante ocho o nueve días su habitual sosiego por aquellos turbulentos y entusiastas congresistas, que en grupos numerosos iban y venían, llenaban cafés, fondas y casas de huéspedes, y pronunciaban mañana, tarde y noche, fogosos discursos en el teatro Moratín. La prensa informativa local, tan mesurada, siempre, tan enemiga de estridencias, tan cauta en dar noticias que escandalicen a su público, creyóse obligada - ¡tal era la conmoción que el congreso produjo!- a recoger en sus columnas la noticia del suceso de cuya importancia y trascendencia no se daban cuenta; sin embargo, ¡cuán lejos estaban de pensar aquellos periodistas y las clases acomodadas de Córdoba que estaban presenciando la celebración del primer congreso anarquista del mundo"1 3 .

Pero igualmente relevante son sus descripciones de las agitaciones campesinas de las últimas décadas de siglo ${ }^{14}$ hasta llegar a 1902, año en que se instala en Bujalance. Su discurso a partir de estas fechas toma una nueva dimensión, en la que percibe claramente su estrategia metodológica de participación. Su descripción del período de huelgas agrarias en Andalucía, que comienza a primeros de siglo posee un especial interés. Aunque el material em-

11. De nuevo los hallazgos de A. Miguel Bernal completan y fundamentan la interpretación de Díaz del Moral en muchas de estas acciones, encontrando en ellas una vinculación con los "pleitos de señorios" cf. A. Miguel Bernal, La propicdad de la tierra... op. cit., pp. 130-133. Igualmente cf. los excelentes materiales aportados por A. María Calero, Movimientos sociales en Andalucia (Madrid: Siglo $\mathrm{XX1}, 1976$ ), passin.

12. Aún cuando esta parte de su discurso tiene menor interés y contiene algunas imprecisiones de fechas posee, por su claridad de exposición y correcta interpretación, en líneas generales, un valor nada desdeñable de carácter divulgador; sobre todo si se tiene en cuenta en la época en que fue escrito. Este hecho revaloriza desde la perspectiva de la praxis intelectual la obra de Díaz del Moral, considerada desde la perspectiva del regeneracionismo conservador católico como un trabajo parcial, aunque bien documentado (Cf. S. Aznar Despoblación y colonización, Barcelona: Labor, 1930 , p. 127). Especial interés tiene el relato de la legada a España del enviado de Bakunin, Giuseppe Fanelli, así couno su acción organizadora de arraigo del movimiento en nuestro país. Existe una reedición del libro-testimonio de un protagonista y espectador privilegiado de estos acontecimientos de 1868 a 1883 . Anselmo Lorenzo El proletariado militante $1 .^{a}$ ed. (1901, tomo I y 1923 tomo II). Reedición en (Madrid: Alianza, 1974).

13. Juan Díaz del Moral, Historia de las agitaciones... op. cit.; pp. 111 y 112 . Dos meses antes, en La Haya, se habría producido la escisión socialista-anarquista, como consecuencia de la polémica bakunianonarxista.

14. Ibid., pp. 99-116. 
pírico directo proviniese de la provincia de Córdoba recoge numerosos datos referentes al resto de Andalucía y fundamentalmente a la campiña de Jaén, Córdoba y Sevilla, donde el movimiento campesino tuvo un extraordinario desarrollo. Su análisis de las huelgas que en 1903 paralizaron gran parte de la campiña alta andaluza posee elementos teóricos de gran interés para conocer la naturaleza del anarquismo campesino andaluz. El abandono de los campos y ganados, así como la custodia de caseríos y cortijos ante la inminente llegada del "nuevo orden" que, sin violencia, supondría la recuperación de su tierra usurpada, que los señoritos les devolverían (en una espera enriquecida durante su transcurso por la privación voluntaria de muchos del alcohol y del sexo) supone una actitud campesina que Díaz del Moral parece insertar en el rechazo a la legalidad moral del orden señorial latifundista por la conciencia histórica del campesinado andaluz. Su descripción de como se introducen en Córdoba las ideas de la Primera Internacional, así como de la creación en los distintos pueblos de la provincia las primeras Sociedades Obreras (en Aguilar, Bujalance, Castro del Río, Espejo, Montilla y en otras localidades), así como de la represión sistemática, desaparición y resurgir de estas sociedades parece constituir por la humanidad de su relato e identificación con su objeto de estudio (el campesinado) un análisis sociológico de la pequeña tradición del campesinado ${ }^{15}$, es decir, realizado desde la perspectiva del propio actor colectivo de su relato ${ }^{16}$.

Sin embargo el período cuyo análisis posee una mayor relevancia es el comprendido entre 1918 y 1920, que Díaz del Moral bautiza como trienio bolchevista $^{17}$. Durante él los campesinos cordobeses estuvieron en permanente conflicto con los "labradores latifundistas" en una lucha continua por mejorar sus condiciones de vida. Su relato de estas huelgas, muchas de las cuales vivió directamente, así como la descripción de sus líderes y muchas de las personas que en ellas intervinieron, a los que conoció personalmente supone un documento sociológico de incalculable valor, cuya utilización como material empírico ha dado excelentes resultados teóricos ${ }^{18}$.

15. Es éste un concepto teórico elaborado dentro de la tradición intelectual de los Estudios Campesinos, formulado en su esbozo inicial por cf. Robert Redfield, Pcasant Society and Culture (The University of Chicago Press,), pp. 70-73. Este, entre otros ya expuestos son los motivos que nos llevan a considerar a Díaz del Moral como precursor de los Estudios Campesinos.

16. No queremos dejar de destacar los relatos de vida de los campesinos propagadores del anarquismo que dedicaban su existencia a comunicar el mensaje del nuevo orden a sus compañeros, cf. J. Díaz del Moral Historia de las agitaciones... op. cit, pp. 249-251; 253-254 y 256-257.

17. Cf. J. Diaz del Moral Historia de las agitaciones... op. cit., pp. 265-376.

18. Cf. como ejemplo relevante, entre otras investigaciones, Eric J. Hobsbawm Primitive Rebels (Manchester University Press, 1971), pp. 89-90, para una interpretación teórica del contenido anarquista campesino de los sucesos de Casas Viejas basada en los conceptos delimitados por Díaz del Moral y pp. 81-83 para una discusión teórica de análoga naturaleza sobre la vinculación entre el movimiento campesino y el comunismo libertario como doctrina. 


\section{ALGUNAS OPINIONES SOBRE SU OBRA}

Es necesario señalar que la obra de Díaz del Moral (cuyos aspectos más relevantes han sido aquí señalados al objeto de situar su trabajo en el pensamiento sociológico agrario como precursor de determinadas corrientes teóricas dentro del mismo) es bastante desigual. No existe una crítica sistemática que valore globalmente su obra desde una perspectiva multidisciplinaria $^{\mathrm{I}} 9$, dimensión ésta en que se ve plenamente inmerso su enfoque (una razón más para incluirle como precursor de los Estudios Campesinos). Desde la perspectiva de la sociología rural existen varios trabajos que analizan en términos bastante positivos su obra ${ }^{20}$. No sucede lo mismo desde otras perspectivas; así se ha dicho, en mi opinión equivocadamente, que Díaz del Moral no ha podido explicar aquello que describiera como consecuencia del "idealismo orteguista" que poseía su pesquisa ${ }^{21}$, cuando precisamente el argumento central de su obra era atribuir al movimiento campesino español un "socialismo indígena" que se integra al movimiento obrero internacional. Cosa muy distinta es si realmente su intento de fundamentar empíricamente tal hipótesis tuviera o no éxito, pero en ningún caso su idealismo - que ciertamente impregna la totalidad de su obra- puede adjetivarse como orteguista, ya que como afirma Víctor Pérez Díaz, el notario de Bujalance sitúa al campesinado en su análisis en la "perspectiva de sujeto"2 2 y, como ya hemos señalado, algunas páginas de su Historia de las agitaciones campesinas andaluzas alcanza a comprender -como un relámpago de excepcional lucidez en su clase social y en su época- el hecho nuevo de la radical autonomía política y revolucionaria del movimiento obrero. Más aún, Díaz del Moral dice textualmente en el prólogo de su libro:

19. Tan sólo contamos con una esquemática y, a mi juicio, equivocada (como trataré de demostrar a continuación) visión global de su trabajo en el, por otro lado, valioso estudio de Tuñón de Lara (Medio siglo de cultura española 1885-1936. Madrid: Tecnos, 1970; pp. 220-221). Jesús M. de Miguel califíca esta obra, en su trabajo sobre la sociología española, como "el más completo análisis de las escuelas de pensamiento incluídas en las ciencias sociales" hasta ahora realizado en nuestro país (Sociology in Spain. Current Sociology. VO1. 27, n. ${ }^{\circ}$ 1, primavera 1979, p. 157).

20. EI primer trabajo en este sentido se debe a Víctor Pérez Díaz en Pueblos y clases sociales en el campo español (Madrid: siglo XXI, 1974), pp. 7-35. Aún cuando en este trabajo Pérez Díaz no llegue a considerar directamente el trabajo de Díaz del Moral como dentro de la nueva tradición de los Estudios Campesinos (probablemente el carácter todavía de perspectiva histórica para percibir la existencia de esta nueva corriente en el pensamiento social agrario), de hecho al caracterizar su obra atribuye a ésta los rasgos básicos de esta tradición teórica, como veremos después. Un excelente intento de continuar el trabajo de Draz del Moral hasta finalizar la II República, M. Pérez Yruela (La conflictividad campesina en la pfovincia de Córdoba 1931-1936. Madrid: Ministerio de Agricultura, 1979) hace un valioso análisis de la obra de Díaz del Moral y da continuidad teórica a varias de sus aportaciones. No obstante, también en este trabajo se apuntan algunas de sus defíciencias, aunque sin llegar a un análisis en profundidad de las mismas. Para una esquemática evaluación del aspecto sociológico agrario de la obra de Díaz del Moral en un contexto teórico más amplio cf. E. Sevilla Guzmán "Noticia sobre un homenaje campesino a Juan Díaz del Moral y aproximación a su función histórica como intelectual" en Axerquia: Revista de Estudios Cordobeses $\mathrm{n} .{ }^{\circ} 1$, Octubre $1980 ;$ pp. 319-325.

21. Información Comercial Española; abril, 1964.

22. V. Pérez Draz, Pueblos y clases..., Op. cit., p. 9. 
"Escribo, pues, este libro con la mirada puesta en el porvenir, tengo fe inquebrantable en los destinos (del obrerismo), y aliento la esperanza de que resucitará algún día",23.

Tuñón de Lara toma la tesis de este anónimo crítico y parece atribuir a Díaz del Moral en su análisis el papel de intelectual tradicional gramsciano. En efecto, aunque no se refiera explícitamente a él, cuando utiliza tal esque. ma teórico, el cual es, en mi opinión, correctamente aplicado (en una original reelaboración) para analizar la función histórica de Ortega como intelectual, sitúa a éste en "una corriente intelectual de quienes sienten la llamada por esa misión (convertirse en cuadros, consejeros e ideólogos de la burguesía que aspiraba al poder)" del cual "Ortega es el más grande de todos ellos"2 4 . Sin embargo su juicio sobre Díaz del Moral queda explicitado cuando afirma que "la ideología" del autor se revela precisamente en el criterio de no obtener conclusiones, ni siquiera hacer algunos planteamientos que preocupan a los estudiosos de la historia"25. Sobre todo si se tiene en cuenta que en la exposición de sus "hipótesis de trabajo ha definido el concepto de ideología, en la acepción que utiliza al caracterizar la praxis intelectual de Díaz del Moral, como una "conciencia social deformadora, en la medida que refleja unos intereses y que puede tener función de justificación en una conducta social o de señalamiento de objetivos deseados con dependencia de su mayor o menor realidad" con la función de enmascarar la realidad, de "intoxicar" el conocimiento científico, de presentar unos hechos y de sus conexiones ${ }^{26}$. Insistimos en que Tuñón de Lara no escribe esto pensando en Díaz del Moral

23. Juan Díaz del Moral, Historia de las agitaciones... op. cit.; p. 24.

24. M. Tuñón de Lara, Medio siglo de cultura... op. cit.; p. 226. Tiene interés que recojamos, aún cuando sea un párafo extenso, aquel en el que Tuñón realiza la reelaboración teórica de la teoría gramsciana de la función histórica del in telectual para aplicarlo a la ideología elitista y tutelar del regeneracionismo burgués. Dice Tuñón: "Una clase como aquélla, que reclama el Poder, del que ha sido apartada - to tal o parcialmente- por una cuasi-parálisis histórica, tiende a considerarse representante de la totalidad social, ello se expresa en la idea orteguiana de "nacionalizar" las instituciones. Pero el drama de esa clase es que acude a la cita de la historia con casi un siglo de retraso, cuando la contradición que la opone a quienes detentan el poder ha sido ya "doblada" por una nueva contradicción, que procede de la inflexión ejercida en la sociedad por el desarrollo de las fuerzas de producción: el cuarto estado está ahí y sus aldabonazos resuenan pavorosamente a partir del año 17. Pero la coyuntura histórica pensada desde esa clase, que aspira a la hegeunonía está vista como síntesis "conciliadora" realizada bajo su dirección. El ideólogo se considera llamado a ser mentor de la sociedad entera. Esto es lo que llamamos misión de "consejero del Príncipe", siguiendo - aunque no hasta sus últímas consecuencias-la idea de Gramsci de que "el príncipe unoderno, el mito-príncipe, no puede ser persona real, un individuo concreto; tiene que ser un organismo, un elemento complejo de una sociedad, en la que ha podido ya empezar a concretarse una voluntad colectiva reconocida en la acción en la que se ha afirmado parcialmen. te" (A. Gramsci, Oeuvres Choisies, París: 1959; p. 186).

"El 'Príncipe', en el caso concreto español (a diferencia de la hipótesis gramsciana, en que equivale al partido político), puede ser la sociedad entera, el pueblo, si empleamos ese término, y por encima de él, los órganos de decisión en manos de "los mejores" orientados por la élite intelectual de esa sociedad. Pero para llegar ahi hay que explicarse por qué está llamada a mandar y a aconsejar esa minoria, hay que buscar el derecho o la justificación de esa hegemonia" (Ibi., p. 226).

25. M. Tữón de Lara, Medio siglo... op. cit., p. 220.

26. Ibid., pp. 13-14. 
en forma directa, pero al no establecer - como hiciera Ortí cinco años más tarde-- una tipología de corrientes intelectuales regeneracionistas incluye en 'l piadoso cajón de sastre de los lamentos l' desvarios de un pucblo menor de edad del regeneracionismo conservador a muy diversos intelectuales. De alguna forma Tuñón de Lara trata de mitigar la dureza de este tratamiento cuando se refiere a Díaz del Moral. Así, afirma que con su Historia de las agitacione's campesinas anclaluzas "uniendo la riqueza de las fuentes, desde las actas manuscritas de la Intermacional hasta el más modesto periódico obrero, Díaz del Moral crea verdaderamente un 'modelo' de historia social en nuestra patria. Un tema tan preciso como es el de su parte esencial: la agitación de los trabajadores agricolas de Córdoba, va encuadrado en una prehistoria que se remonta a la Edad Media, una historia del movimiento obrero internacional 1 . nacional en los primeros veintidos años del siglo. La parte central es un ejemplo, rara vez igualado, de exposición de un tema monográfico de historia del movimiento obrero (o campesino), en que se conjugan fuentes casi exhaustivas y experiencia personal. El relato se eleva muy por encima de la crónica y constituye una fuente imprescindible de trabajo"2 7 . En cualquier caso, Tuñón reduce la obra de Díaz del Moral al "relato" aún cuando sea una fuente imprescindible de trabajo". Más aún, da a entender que su trabajo carece de un contenido teórico al atribuirlo el criterio de no obtener conclusiones cuando en realidad es el propio Tuñón quien no sabe o no quiere ver la existencia de éstas (como ahora veremos).

Ya hemos señalado como central en la obra de Díaz del Moral la hipótesis de un socialismo indígena en el campesinado andaluz, que trata de fundamentar empíricamente con su "relato" y "la altura" de la observación participación en busca de la pequeña tradición del campesinado cordobés. ¿No es ésto acaso plantear el problema -no solo preocupación de los estudiosos de la historia social, sino de cualquier científico social que estudia Andalucíadel porqué del anarquismo andaluz $?^{28}$.

Como ya ha señalado uno de los investigadores que más a fondo ha estudiado hasta la fecha el legado intelectual de Díaz del Moral: "Las c'onclusiones de carácter teórico que se extraen de la Historia de las agitaciones campesinas andaluzas constituyen hoy un punto de referencia ineludible en cualquier investigación que se realice sobre los movimientos campesinos, al tiempo que es también una fuente de sugerencias y motivo de reflexión para el movimiento obrero hoy. Díaz del Moral demostró que los movimientos

27. Ibid., p. 220. Obsérvese la contradicción entre su cualificación de Draz del Moral y la aceptación -quizá inconsciente- de una praxis intelectual progresista como se desprende de Io por nosotros subray ado en este juicio.

28. Tữón también acusa a Díaz del Moral de no plantearse la euestión del posterior auge del socialismo andaluz, probablemente porque ignora que aunque su obra se publicó en 1929, ésta quedó concluida varios años antes de su publicación. Y, sobre todo, porque como ha demostrado Antomo María Calero, en Ios años en que fue escrita la obra de Díaz del Moral (y en muchos aspectos hoy en día también) el campesinado andaluz veía la cuestión social desde una posición de clase, sin diferenciar las distintas concepciones socialistas del problema desde la "gran tradición". 
campesinos pasan por etapas de exaltación y depresión periódicas y comprobó también que los movimientos son más intensos en épocas de prosperidad económica que en épocas de gran penuria. Demostró asimismo la importancia que los líderes tuvieron en la organización y el mantenimiento del movimiento obrero. En relación a las estrategias campesinas, en su libro se pone de manifiesto como el movimiento campesino fue progresivamente pasando de una etapa inicial en la que predominaba la espontaneidad $y$, hasta cierto punto, la ingenuidad en algunos planteamientos reivindicativos, en los que no se tenía en cuenta la fuerza real que el estado podía ejercer en la represión de las luchas sociales, a etapas posteriores de mayor realismo por parte de los trabajadores. También son de gran interés las reflexiones que hace sobre la forma en que los propietarios intentaron dar respuesta aquella avalancha de conflictos y reivindicaciones sociales. En definitiva, la Historia de las agitaciones campesinas andaluzas no es solo una pieza histórica de gran valor, sino también un libro del que pueden extraerse lecciones válidas para el movimiento campesino hoy",29.

En definitiva, el excelente análisis de Tuñón de Lara sobre el regeneracionismo español posee el valor de haber introducido "lo que no se había hecho nunca, la dimensión de la investigación y del pensamiento sociales, la obra de un Díaz del Moral o de un Pascual Carrión y, sobre todo, un elemento todavía más nuevo, la marcha del pensamiento marxista a la búsqueda de sí mismo, de Jaime Vera a Manuel Núñez Arenas". Sin embargo a la objeción que le hace Pierre Vilar de "excluir la cultura catalana de la cultura española",3 0 hay que añadir la desfigurada imagen que el sesgo de su antianarquismo introduce en su pesquisa al analizar la obra de Díaz del Moral. ¿Cómo si no se puede atribuir un carácter "reformista institucionalista" a "la evidente simpatía de Díaz del Moral por el anarquismo" cuando dice que la causa fundamental de su postración... es la incultura y la inconsecuencia de las masas", 1 . ¿No puede interpretarse también esta afirmación como causa de esta simpatía por el movimiento sindicalista?.

29. Manuel Pérez Yruela "Charla pronunciada en la apertura del homenaje a D. Juan Díaz del Moral" (Bujalence, abril, 1980). En este homenaje del pueblo de Bujalence a su paisano se pretendió -en palabras del Alcalde del Ayuntamiento (promotora esta institución, junto a la familia de Díaz del Moral, del mismo)- "no sólo devolver a la memoria colectiva de nuestro pueblo su gran figura depurada" junto a tantas otras, por la Junta de Responsabilidades Políticas de la dictadura franquista, sino también rendir homenaje a todo un pueblo y a sus líderes, a aquellos hombres que él conoció y de quienes nos habla en su libro". En este acto de reconocimiento a Díaz del Moral el homenaje de hecho - e interpretando así la comisión organizadora la praxis intelectual de Díaz del Moral- se hizo extensivo no sólo al movimiento campesino y los líderes que analizó el ilustre bujalanceño, sino a otros líderes campesinos posteriores que en Bujalence, Castro, Espajo, Córdoba y Andalucía fueron represaliados "por su oposición al franquismo". Para una breve crónica de este atípico homenaje "realizado en el marco de una comunidad rural y desde Ia inquietud social y cultural del campesino andaluz" cf. E. Sevilla Guzmán, Noticia de un homenaje campesino a Diaz del Moral... op. cit. pp. 319-325; pp. 319-321.

30. Pierre Vilar, "Manuel Tữón de Lara: Una vocación, un obra, un creador de encuentros" en Estudios sobre Historia de España. Homenaje a Tuñón de Lara (Madrid: Univ. Internacional M. Pelayo, 1981); pp. 1-5; p. 4 .

31. M. Tuñón de Lara, Medio siglo... op. cit.; pp.220-221. Sobre la otra idea-fuerza ideológica que 


\section{DIAZ DEL MORAL COMO PRECURSOR}

La interpretación que Tuñón de Lara realiza de Díaz del Moral basándose en un superficial análisis de su obra es totalmente insuficiente para insertar a éste en su remodelación teórica del esquema gramsciano de explicación del papel del intelectual en la dinámica de transformación histórica, el cual, en mi opinión, habría de completarse ya que no basta con resaltar que todo intelectual se encuentra orgánicamente ligado a la sociedad civil y, por tanto, su producción es el resultado de una articulación dialéctica entre los intereses de clases, grupos de pertenencia y de referencia y, en definitiva, del entramado social. Ello hace de él un ser político, ideológico y organizador intelectual de la realidad social que trata de explicar anclado en un contexto intelectual concreto, en el que la situación sociopolitica determina la existencia de varias alternativas y no de una sola, como parece desprenderse de su esquemática construcción teórica, ya que ni en sus "hipótesis de trabajo" ni en su pincelada remodeladora del "consejero del Príncipe" presenta un marco teórico suficiente para entender otro papel de intelectual distinto de éste o su antagónico. Además su análisis de los diferentes esquemas de valores que permiten obtener las concepciones del mundo hegemónicas es insuficiente, como ya hemos apuntado con anterioridad al no percibir los diferentes fenómenos culturales periféricos al regeneracionismo (caso de Díaz del Moral) o al regeneracionismo populista de Joaquín Costa. Por otra parte, el intelectual en su intento de objetivar y explicar la realidad social articula la sociedad civil y política de acuerdo con su proyecto ideológico específico. Su producción intelectual no tiene, ciertamente, un carácter autónomo e independiente de los procesos sociales, sino que va unido a ellos racionalizando y legitimando unos intereses de clases. Pero tal actividad de racionalización y de legitimación de los intelectuales posee un carácter dinámico vinculado a la transformación del proceso histórico de cambio de las estructuras culturales, sociales y políticas, tal como ellos, los intelectuales, lo perciben siempre dentro de su coyuntura histórica y contexto intelectual. Lo cual, en el caso de Díaz del Moral, no es tampoco suficientemente tenido en cuenta por Tuñón. Bien es cierto que en la actualidad no contamos con datos suficientes para realizar este tipo de análisis sobre Díaz del Moral. El material historiográfico

Tuñón atribuye a Díaz del Moral respecto a los ciclos de exaltación y depresión anímica cf. los trabajos de M. Pérez Yruela y V. Pérez Díaz ya señalados, en que, sin referirse a Tuñón, falsean este aserto al hacer una interpretación y valoración, que sin ser positiva en todos sus aspectos, es radicalmente distinta a la del ex-profesor de la Universidad de Pau.

32. Semblanza sobre la vida y obra de don Juan Díaz del Moral (Málaga: Imprenta de la Universidad, 1980), 31 p. Parte del trabajo más amplio, ya citado, en Revista de estudios regionales n. ${ }^{\circ} 4$. 
sobre él acumulado es muy exiguo. En efecto, aparte de lo ya apuntado sobre su obra, respecto a su vida prácticamente tan solo contamos con el apasionado estudio de su nieto Antonio Tastet Díaz ${ }^{3}$ que, aunque ofrece algunos materiales de gran interés, no es sino el comienzo de una investigación en curso, ya que los artículos aparecidos en semanarios y periódicos no responden a una investigación real sobre el tema. Aún así, en otro trabajo hemos esbozado, a modo de hipótesis, algunas ideas para comprender desde esta situación de insuficiencia del conocimiento, tanto historiográfico como sociológico, al carecer de herramientas de análisis suficientemente elaboradas, la función histórica de Juan Díaz del Moral como intelectual. Puede tener interés, a pesar del carácter de ensayo sin pretensiones académicas, alguna de las conclusiones de aquella breve reflexión ${ }^{3}{ }^{3}$. Así, decíamos en aquel ensayo que, aunque respecto a los modos y formas de vinculación de Díaz del Moral a distintos grupos sociales de su época, los datos de que disponemos no nos permiten llegar a conclusiones mínimamente sólidas, si consideramos el período de su producción intelectual (el libro quedó inscrito en 1923 y de su lectura parece desprenderse que antes de 1918 ya realizaba en forma sistemática la acumulación de material empírico) observamos que, aún cuando se encontraba claramente integrado a la comunidad intelectual del ámbito de la Institución Libre de Enseñanza, dentro del más puro pensamiento liberalburgués de la época, su posición entre los "intelectuales" es significativamente excepcional. En efecto, como ha señalado Víctor Pérez Díaz, aunque casi todos los intelectuales de la época "trataron de implicarse, o estuvieron dispuestos a hacerlo en algún momento de sus vidas, en los movimientos liberales y radicales del momento... la experiencia resultó ser para ellos de incertidumbre e impotencia. Quedaron, pues, fijos ante el país; al tiempo, obsesos y distantes", fueron como espectadores "a los que el sentimiento de rechazo que resulta de la anticipación del propio fracaso y del sentido de la propia impotencia neutraliza los urgentes e irreprimibles deseos de intervenir". Por el contrario Juan Díaz del Moral, a través de su obra, adopta una actitud radicalmente distinta. Así, al analizar la evolución política del campesinado en Andalucía, lo hace con el claro propósito de hacer ciencia social con el compromiso de conducir "su investigación hasta sus últimas consecuencias" 34 .Su perspectiva de análisis le hace ver la situación andaluza como un todo articulado situando la naturaleza del conflicto campesino en el foco de su atención. Y su marco teórico se centra en torno a la determinación de un proceso social, el movimiento campesino, y su identificación no como resultado de elementos constantes en las distintas situaciones sociales consideradas sino a través del análisis de su estructura interna y concretamente de los factores psicológicos, culturales y sociales que permiten su desarrollo"35 . No es este

33. E. Sevilla Guzmán, "Noticia sobre un homenaje... op. cit."; pp. 319-325.

34. Víctor Pérez Draz, Pueblos y clases sociales... op. cit. pp. 8 y 9.

35. E. Sevilla Guzmán, "Noticia sobre... op. cit." pp, 324 y 325. 
lugar para valorar la fertilidad o no de este enfoque, ni para analizar críticamente su obra (que ha sido en sus aspectos genéricos considerada anteriormente). Lo relevante en nuestro discurso es que del enfoque teórico y la perspectiva de análisis de la obra de J. Díaz del Moral se desprende, por un lado, un compromiso del autor con los intereses del campesinado y, por otra su clara inserción en el pensamiento social agrario como precursor de los Estudios Campesinos.

"Esto no obstante no nos permite en absoluto situar su papel como intelectual en su época. En efecto, su intento de fundar un Bloque Agrario que agrupara a todos los agricultores, grandes y medianos propietarios, junto a arrendatarios y aparceros y al resto del campesinado con tierra para la defensa de los "intereses olivareros" parece entrar en contradicción con el compromiso que se deduce de su producción intelectual. De igual forma su militancia en la Agrupación al Servicio de la República, formación política poco estudiada pero de ideología no exenta de ambigüedad, y su participación en la práctica de la reforma agraria de la Segunda República nos muestran cuanto queda aún por esclarecer en cuanto a la investigación historiográfica se refiere para comprender la vida pública de Juan Díaz del Moral"36.

Sin embargo, "si cualquier trabajo científico dista mucho de ser un objeto neutral desprovisto de los valores y asunciones que subyacen en el compromiso vital de su autor, Historia de las agitaciones campesinas andaluzas explícita éstas de tal forma a través de su perspectiva teórica y su enfoque de análisis, que se sitúa a años luz de una supuesta neutralidad. Los protagonistas del libro: el movimiento campesino, el estado liberal y los terratenientes andaluces - me refiero a la parte central del libro desde el último tercio del siglo XIX hasta el primer cuarto del XX- son analizados desde unos supuestos teóricos en los que el campesinado adquire la "perspectiva de sujeto" mostrando las acciones de clase que ésta lleva a cabo y su enfrentamiento al nuevo orden capitalista entonces emergente.

Aún cuando en su obra se advierte, en determinados momentos, una cierta dimensión paternalista, en otros diríase que su identificación con el campesinado es tal que sus conceptualizaciones son producto de la utilización de las propias categorías analíticas con que el campesinado ve el mundo. Su análisis del trienio bolchevista ( za clásica para la nueva orientación teórica de los Estudios Campesinos",3 7 .

36. E. Sevilla Guzmán, "Noticia sobre... op. cit." p. 325.

37. E. Sevilla Guzmán, "Noticia sobre un homenaje... op. cit." p. 325. 
En cualquier caso, el análisis de su obra ${ }^{3}$ no permite clasificar en absoluto a Díaz del Moral como un "intelectual tradicional" en el esquema de análisis esbozado por Tuñón de Lara y más arriba considerado. Su estudio de los movimientos campesinos en un claro intento de encontrar el hilo conductor que enlace los motines de la "prehistoria campesina" con las modernas agitaciones "fecundadas por la corriente del obrerismo" -y esto al margen de éxito o fracaso de dicha empresa- parece explicitar su praxis intelectual.

38. El análisis de la obra de Díaz del Moral hasta aquí realizado se basa exclusivamente en su trabajo Historia de las agitaciones campesinas andaluzas. No obstante para considerar, en rigor, su obra habría que incluir su trabajo Las reformas agrarias europeas de la postguerra 1918-1929 (Madrid: Editorial Revista de Derecho Privado 1967). Dicho trabajo carece de relevancia en lo que a sus aportaciones a la sociología rural se refiere, ya que no es sino un análisis de las legislaciones de tales reformas agrarias, Ias cuales no legaron aplicarse en múltiples aspectos. No obstante en dicho trabajo Díaz del Moral considera la reforma agraria, desde una, dimensión fundamentalmente política, como un trasvase de la propiedad de la tierra de unas clases a otras realizándose así una reestructuración de la sociedad "con arreglo al programa de convivencia que utilizó como bandera" el grupo social que la lleva a cabo. Tal definición que analiza el concepto en su raíz, posee un indudable valor teórico. Cf. Manuel Pérez Yruela y E. Sevilla Guzmán "La dimensión política en la reforma agraria: Reflexiones en torno al caso andaluz", en Papers. Revista de Sociología n. ${ }^{\circ} 16$ Especial dedicado a Andalucía, 1981; pp. 53-91. 